\title{
Design Parameters Calculation of a Novel Driveline for Electric Vehicles
}

\author{
J. Santiago ${ }^{1}$, J. G. Oliveira ${ }^{1}$, J. Lundin ${ }^{1}$, J. Abrahamsson ${ }^{1}$, A. Larsson ${ }^{1,2}$ and H. Bernhoff ${ }^{1}$ \\ ${ }^{I}$ Division for Electricity, Dep. of Eng. Sciences, Uppsala University \\ P.O. Box 534, SE-751 21 Uppsala, Sweden \\ Email: juan.santiago@angstrom.uu.se \\ ${ }^{2}$ Swedish Defence Research Agency (FOI), Defence \& Security, Systems and Technology \\ SE-14725 Tumba, Sweden
}

\begin{abstract}
A driveline for electric vehicles is presented. The propulsion system is operated at a higher voltage than the primary energy source. The batteries selected as the primary energy source deliver power to the vehicle through a motor-generator wounded with two electrically isolated sets of windings, named Two Voltage Level Machine (TVLM). The dynamic behaviour of a vehicle operating according to a standard drive cycle is studied. Parameters of the driveline such as power rates and size of the flywheel are obtained by optimization. A description of the performance of a TVLM is also presented through its equivalent circuit and the control of the machine. Special attention to the system losses is presented. A scale prototype has been constructed and tested under a drive cycle, demonstrating the system performance of the system.
\end{abstract}

Keywords: Flywheel, Electric driveline, Regenerative braking, Simulation

\section{Introduction}

One of the main challenges in order to make electric cars competitive with gas-powered cars is in the improvement of the electric power system. Batteries are the main energy storage system of today's electric vehicles. The improvements in terms of energy density have been tremendous in recent years but range and life time are still low compared to vehicles propelled with conventional combustion engines. The performance of all-electric vehicles is still not sufficient to satisfy today's drivers who are used to the high energy density of fossil fuels as energy carrier.

To minimize the number of charge/discharge cycles of the battery, a flywheel can be integrated in the driveline [1]. The flywheel then handles the transient energy flow to the wheels (while accelerating or driving at constant speed) or from the wheels (while braking) whereas the battery operates under optimal conditions, preferably under steady and smooth discharging. Especially in urban traffic this could decrease the number of charge/discharge cycles, and thereby increase battery life.

Since a flywheel system is constantly in use during driving, an important part of its design deals with the minimization of losses. The principle losses associated with the motor/generator of a flywheel are drag losses, eddy current losses in stator [2] and rotor and mechanical losses in the bearings. To this end, the system is housed in an air-tight vacuum chamber. An optimized motor topology is selected, with two synchronous rotors and one stator, allowing the magnetic flux a stationary return path (in the reference frame of the rotor). Furthermore, the use of magnetic bearings as suspension for the rotor reduces the losses at high 
rotational speeds. Their frictionless operation results in negligible wear and reliable operation in vacuum as no lubrication is needed.

This paper presents a new electric driveline with an integrated flywheel [3]. Simulations show the improvements in the driving efficiency and the reduction of stress in the battery.

\section{Driveline Description}

Batteries and fuel cells are the Primary Energy Sources (PES) in modern electric vehicles [4] and work intrinsically with low voltage while traction motors work more efficiently at a higher voltage. Traditionally the electric vehicle driveline is based on a single DC power bus link $[4,5]$. Fig. 1 shows an alternative driveline, adapted to the requirements of these two main systems. The novelty is that the system operates with two different voltage levels. The presence of a flywheel guarantees a smooth energy flow from the PES, reducing the power stress and increasing the efficiency and lifetime of the components.

The system additionally adds freedom in the choice of PES. Presently high power traction battery systems are implemented in many automotive applications. With the addition of the flywheel, low power battery packs with large specific energy and long life may be used, prolonging the range of the vehicle.

The high voltage side of the Two Voltage Level Machine (TVLM) is linked bi-directionally to the wheel drives. When the vehicle brakes, the energy is recovered and stored in the flywheel. For long regenerative braking times the energy flow is reversed from the flywheel to recharge the battery.

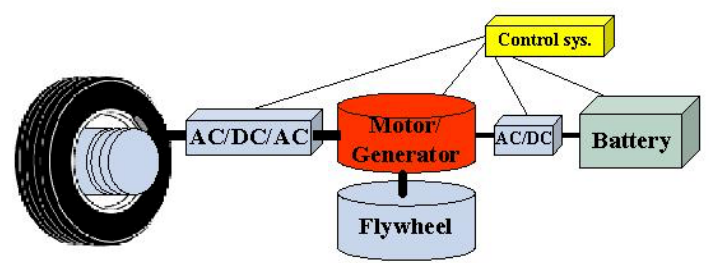

Figure 1: Two voltage level driveline configuration with a Two Voltage Levels Machine (TVLM).

\section{System Parameters}

The driveline description presented is made up of several subsystems that need to be well defined to obtain an optimal performance of the system. The specifications and dynamics of the vehicle are used to obtain the optimal power delivered by the PES, the power delivered at the high voltage side and the inertia of the flywheel. The rest of the parameters needed to define the driveline components are obtained by maximizing the overall efficiency of the system.

The low voltage level is determined by the primary energy source and the high voltage level by the wheel motor specifications. The main design parameters of the system are the TVLM power at low and high voltage and the energy storage of the flywheel.

The optimum peak and average power consumption depends on the characteristics and applications of the vehicle. The sizing of the system is made through optimization of the performance of the vehicle in standard drive cycles. The power level of the high voltage side is selected to handle the peak power requirements whereas the power level of the low voltage side, as well as the power rate of the PES, is chosen to handle the average power of the drive cycle. In this way, the flywheel smoothes the power transients and protects the PES from power peaks. The storage energy capacity of the flywheel is therefore selected to ensure steady power delivery from the PES. The weight and losses of the flywheel increase with storage capacity, so there exists a trade off between energy storage capacity of the flywheel and capacity of power delivery of the PES.

Fig. 2 shows the power demand simulated at wheel shafts of an ordinary vehicle during a standard FTP 75 (Federal Test Procedure) urban drive cycle. The vehicle considered for this simulation has a mass of $1500 \mathrm{~kg}$, a dimensionless drag coefficient $\mathrm{C}_{\mathrm{w}}$ (also known as $\mathrm{C}_{\mathrm{x}}$ ) of 1.35 , and a frontal area of $1.73 \mathrm{~m}^{2}$. As seen, the power demand varies from $34 \mathrm{~kW}$ (when accelerating) to $-29 \mathrm{~kW}$ (when braking) However, the average electric power from the energy storage, needed to propel an ordinary vehicle according to a standard FTP 75 urban drive cycle, is only about $4 \mathrm{~kW}$, i.e. more than eight times less than the maximum power needed during the drive cycle.

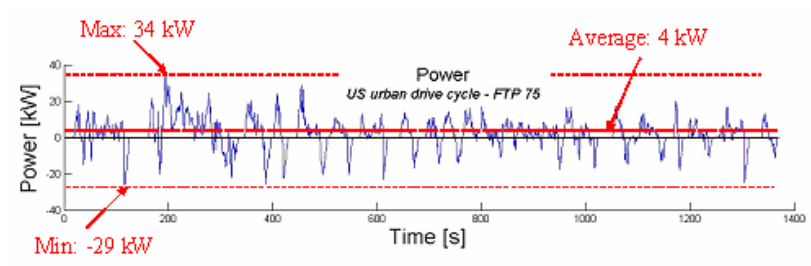

Figure 2: The power-time graph of the FTP-75 drive cycle. 
Instead of transferring all the great variations in power to/from the wheels to/from the battery, the flywheel handles them. Fig. 3 shows another simulation for the same vehicle where the flywheel is taking care of all the transients while the battery is smoothly operating, delivering a constant power of $4 \mathrm{~kW}$. During the whole drive cycle, the difference between the minimum and the maximum amount of energy stored in the flywheel is not more than $1.2 \mathrm{MJ}(0.34 \mathrm{kWh})$. This means that the energy storage capacity of the flywheel, if working solely as a power handling device, only has to be $1.2 \mathrm{MJ}$. If the flywheel is to be used also as significant energy storage and not only as power handling device, it has to be designed to store more energy. This configuration would also enable fast charging as the flywheel can be charged at a very high power to store the energy intermittently. Then the flywheel would be slowly discharged to charge a battery, acting as PES. For a flywheel acting only as a power handling device, no significant amount of energy can be stored and therefore there is no use in charging the battery other than at the end of a drive cycle or during long periods of braking, i.e. in long downhill slopes.

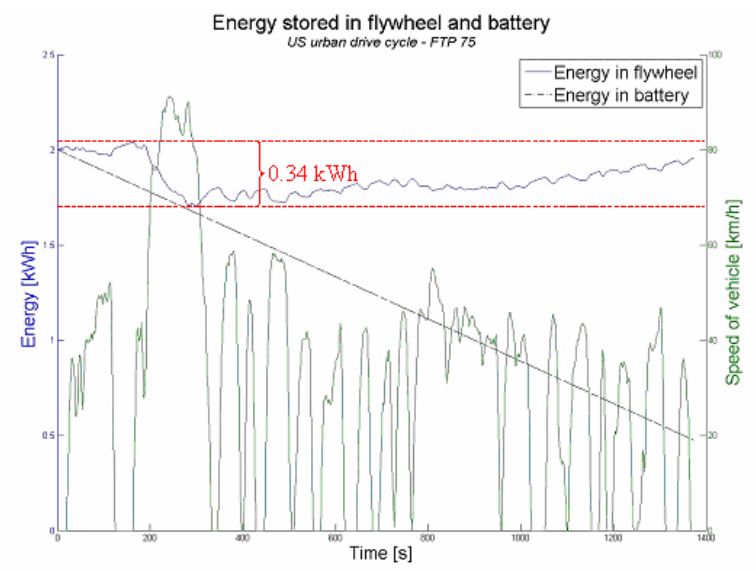

Figure 3: The energy/speed vs. time graph of the FTP 75 drive cycle. The power outtake from the battery (primary energy source) is $4 \mathrm{~kW}$ while the flywheel handles all the transient power flows.

\section{Magnetic Bearings}

Active magnetic bearings have in the last years become a realistic option outside specialized research applications, mostly due to the availability of real-time calculation hardware and power electronic components at affordable prices [6]. Since the magnetic bearings have no physical contact, frictional losses become completely eliminated. There is, additionally, no need for lubrication, which is advantageous in a system that is designed to work in vacuum.

The main losses that do exist in such a suspension system are resistive power losses in the coils, eddy-current and hysteresis losses in the core [7]. At high rotational speeds, these losses may become significant if the system is not properly designed. Minimization of these losses is important not only in order to minimize the total losses of the system, but also in order to ensure that the rotor does not heat up excessively. This is especially important in a permanent magnet machine where the rotor must not be allowed to surpass a certain temperature in order not to cause demagnetization of the magnets. Since the rotor in a machine with magnetic levitation enclosed in a vacuum chamber does not have any physical contact with the housing, it is not able to dissipate energy efficiently.

\section{Equivalent Circuit}

An equivalent circuit of a TVLM has been developed [8]. The machine is assumed to have non salient, permanent magnet poles and a stator with two electrically isolated sets of three phase windings. The winding sets have a different number of turns and therefore are operated at different voltage levels, named high $(\mathrm{H})$ and low (L). There is a magnetic coupling between the rotor and both sets of windings and also between high and low voltage winding. The power flows from the low to the high power side in a similar way as in a transformer due to the mutual inductance. The output power is, however, not determined by the input power as in transformers. The difference between the two is the energy stored or delivered by the flywheel. There are three main modes of operation:

- The high voltage side is acting as a generator and the low voltage side as a motor.

- The high voltage takes the energy from the regenerative braking and both sides act as motors. The energy is storage in the flywheel.

- The low voltage side acts as a generator and recharges the battery.

Fig. 4 shows an equivalent circuit of the first operation mode, that is, when the high voltage side is acting as a generator and the low voltage side as a motor. The machine operates in the other operational modes have the same equivalent circuit, and only differs in the loads and drives coupled to the machine terminals. 
The TVLM can be evaluated as two synchronous machines with a magnetic coupling and common rotor speed. Fig. 4 shows the equivalent one phase circuit.

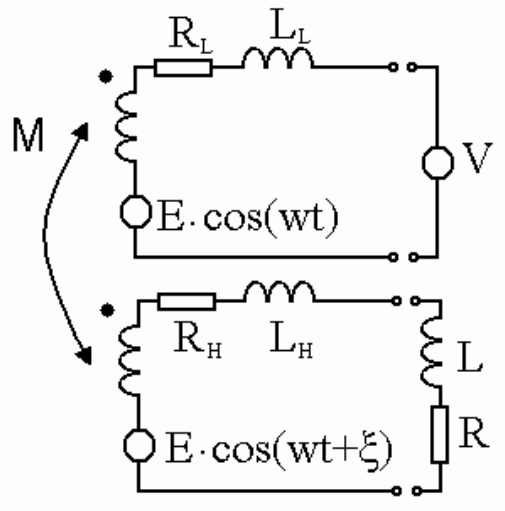

Figure 4: Machines equivalent circuit.

For the operational mode shown in fig. 4, the voltage equations can be written as:

$$
\begin{aligned}
& E_{H}=\left(Z_{H}+Z\right) \cdot I_{H}+L_{H L} \cdot I_{L}+V_{H} \\
& V_{L}=Z_{L} \cdot I_{L}+L_{H L} \cdot I_{H}+E_{L}
\end{aligned}
$$

Frequency of both sides is determined by the rotor speed. The two windings are placed in the stator shifted by $\xi$ electrical degrees. To minimize the harmonic content in dual-star synchronous machines this angle is optimum at $30^{\circ}$ [9], but not for a TVLM. For an arbitrary $\xi$ shift angle the electromotive forces can be written as:

$$
\begin{aligned}
& E_{H}=\psi_{M} N_{H} w \cos (w t) \\
& E_{L}=\psi_{M} N_{L} w \cos (w t+\xi)
\end{aligned}
$$

The mutual inductance depends on the angle $\xi$. Fig. 5 shown the effect of the mutual inductance between the winding sets. The equivalent circuit equations (1) and (2) have been solved for an angle between windings of $90^{\circ}$.

Figure 5: Equivalent circuit simulation. For a $\xi$ angle between windings of $90^{\circ}$ the mutual inductance opposes the electromotive force.

\section{Motor Control Simulations}

A flywheel energy storage system based on a TVLM contains two different bidirectional Power Converter Systems (PCS): an AC/DC/AC converter on the high voltage side, connecting the flywheel motor/generator to the wheel motor and an $\mathrm{AC} / \mathrm{DC}$ converter on the low voltage side, connecting the flywheel motor/generator to the PES (batteries or fuel cells).

The battery system (LV side) starts the motor and works as a backup, recharging the flywheel energy (by increasing its rotational speed) every time it reaches a certain minimum energy level (indicated by a minimum rotational speed). It also sends the energy stored in the flywheel back to the PES during recharging.

\subsection{Motor Control}

Speed control is used when the flywheel is driven as a motor by the LV PCS. The two primary reasons are process control and energy conservation, but other benefits can be obtained [10]. Fig. 6 shows a block diagram of the motor speed control, which is based on reference [11].

Position sensors are distributed along the stator in such way that they generate six different logic states per electrical cycle. The three sensors work as in the six-step technique; however, instead of generating square waves as in six-step modulation, a sine-wave is generated using space vector modulation [12]. A reference speed is compared with the measured speed, and the resulting error is processed by a PID controller. The PID output signal generates the amplitude of the sine wave. The phase is calculated using phase advance, which creates a rotating electrical field in the stator that is 90 degrees ahead of the rotor magnetic field in order to produce the highest possible torque [13].

Figure 6: Block diagram of the motor speed control

A simulation model of the low voltage side of the driveline, with Pulse Width Modulation (PWM) 
and PID controller as described above, was implemented using the simulation tool Dymola. A short drive cycle consisting of two pulses of torque was used. The results can be seen in fig. 7 and 8 .

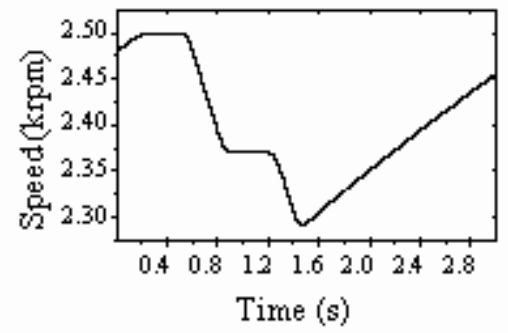

Figure 7: Variation of the rotational speed of the flywheel during the cycle simulated.

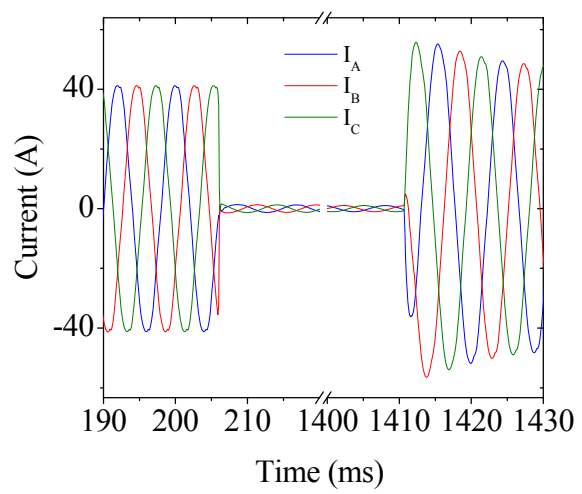

Figure 8: Inverter output current

The current applied to the stator of the machine (after the inverter) is shown in fig. 8. When starting the simulation, current and voltage are applied to the stator winding in order to accelerate to nominal speed. The controlled switch opens once the machine is working at $2500 \mathrm{rpm}$ (nominal speed), and only a small current is circulating in the stator. This moment can also be seen in fig. 7, which shows variation of the speed of the flywheel in time, for the considered drive cycle. The machine slows down when the high torque is applied, which simulates the energy exchange that will take place at the high voltage side of the system. The control system detects speed under the lower limit and once more the machine is connected to the battery.

\subsection{PES System}

The control of the low voltage side PCS ensures a smooth power delivery to increase the lifetime of the PES. Considering the same drive cycle used in the previous simulations, the energy delivered by the battery for a drive cycle can be seen in fig. 9.

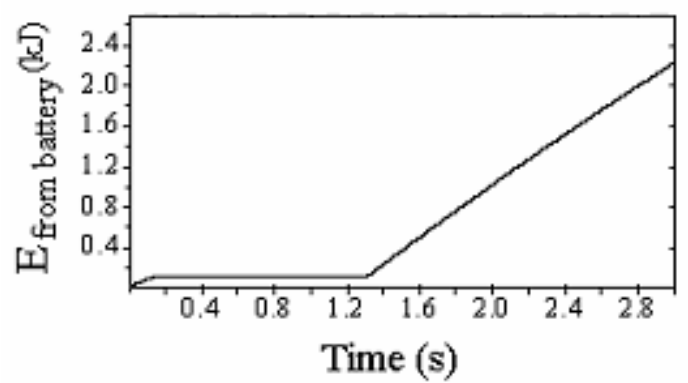

Figure 9: Energy delivered by the battery for a short drive cycle.

It can be seen that, around time $1.2 \mathrm{~s}$, the flywheel speed reaches the minimum limit of $2300 \mathrm{rpm}$ (see fig. 7), and energy start to be extracted from the battery to accelerate the flywheel until its nominal speed.

As distinct from other electric vehicle technologies, the PES is not connected directly to the wheel motor. This way, the battery is not directly affected by the regenerative breaking this energy is absorbed by the flywheel. In the present system, the battery can be recharged when: a) the flywheel speed exceeds a maximum limit or b) when the car stops and all the energy stored in the flywheel is transferred back into the battery.

\section{Test Results}

A scaled TVLM has been constructed to validate the simulations. The machine has an axial flux coreless configuration. Both set of windings are three phase and are mutually magnetically coupled although inductances are very low due to the coreless topology. The stator winding of the scale prototype is shown in fig. 10. Main machine parameters are shown in Table 1.

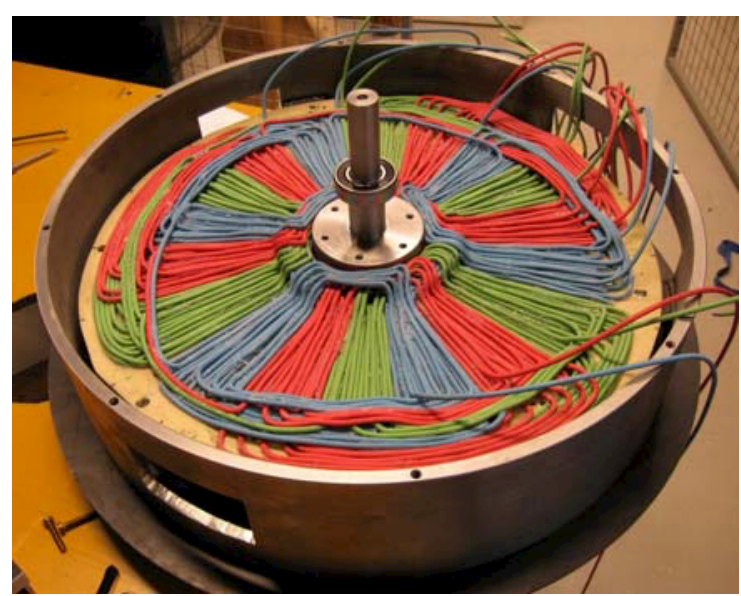

Figure 10: TVLM scale prototype. The upper rotor has been removed to show the stator windings. 
Table 1: Main characteristics of the TVLM prototype tested.

\begin{tabular}{l|c|c}
\hline Number of pole pairs & \multicolumn{2}{|c}{3} \\
\hline Rated speed (rpm) & \multicolumn{2}{|c}{3000} \\
\hline $\begin{array}{l}\text { Number of turns per phase } \\
\text { and pole }\end{array}$ & 12 & 4 \\
\hline Back emf at rated speed & $40 \mathrm{~V}$ & $13.5 \mathrm{~V}$ \\
& $\mathrm{rms}$ & $\mathrm{rms}$ \\
\hline Winding resistance $(\Omega)$ & 0.12 & 0.40 \\
\hline Winding inductance $(\mathrm{mH})$ & 0.19 & 0.019 \\
\hline Mutual inductance $(\mathrm{mH})$ & \multicolumn{3}{|c}{0.079} \\
\hline Moment of inertia $\left(\mathrm{kg} \cdot \mathrm{m}^{2}\right)$ & \multicolumn{3}{|c}{0.34} \\
\hline
\end{tabular}

A scale bench set up has been constructed prior to full vehicle tests. The layout is presented in fig. 11. The low voltage side is driven by the converter described in section 6. The high voltage side is connected to a rectification bridge and a load variable to simulate the traction motor load.

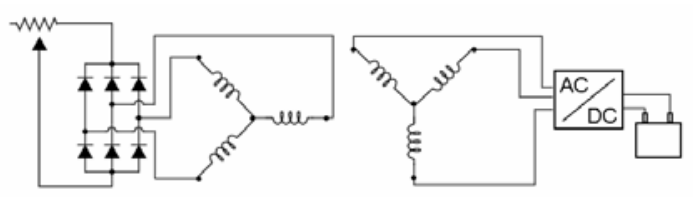

Figure 11: Test layout. The low voltage side of the TVLM is driven by a power converter system. The emf inducer in the high voltage side is connected to a bridge rectifier and a variable resistance.

The variable load applied in the system varied from $20 \Omega$ to open loop, and the variation in power delivered by the batteries and in the load is shown in fig. 12.

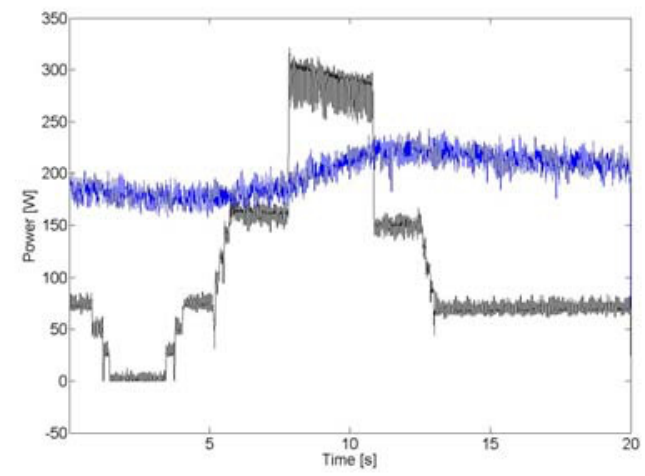

Figure 12: The blue line shows the power delivered by the converter to the low voltage side of the TVLM while the black line shows the power extracted from the high voltage side during a drive cycle.

The difference of energy is absorbed or delivered by the flywheel. The system ensures a steady energy delivery from the battery regardless of the power variation in the load.

\section{Conclusion}

This work introduces a new electric driveline for electric vehicles with two voltage levels. The core component of the system is a double wound flywheel that is operated at two different voltage levels and stabilizes the power transients of the vehicle during a drive cycle. The simulations show that this new electric drive has advantages over the traditional DC power bus.

The standard drive cycle FTP 75 is studied to obtain the optimum power and energy storage capacity of a vehicle driveline. The energy recovered during regenerative braking in the drive cycle is delivered at high power for short periods of time. Flywheels can also be used for fast charging of the vehicle, acting as intermittent energy storage between the high power flow from the grid and the low power flow to the battery.

For a flywheel acting only as a power handling device, no significant amount of energy can be recharged in the battery. In practice the only moments to efficiently recharge the battery are at the end of a drive cycle and during long periods of braking, i.e. long downhill slopes.

Main designs parameters of a Two Voltage Level Machine (TVLM) are discussed and the equivalent circuit and voltage equations of a TVLM is presented.

A scale prototype has been constructed and tested under a drive cycle. The results show that it is feasible to operate the system under variable load and steady power delivery. The new driveline allows vehicle batteries with lower power rating and longer lifetime.

\section{Acknowledgments}

This work was supported by the Swedish Energy Agency and Ångpanneföreningen's Foundation for Research and Development. Prof. Mats Leijon is thanked for valuable help at various stages of this work.

\section{References}

[1] Paul P. Acarnley, Barrie C. Mecrow, James S. Burdess, J. Neville Fawcett, James G. Kelly, and Philip G. Dickinson, Design Principles for a Flywheel Energy Store for Road Vehicles, IEEE Trans on Ind. Appl., vol. 32, no. 6, Nov/Dec1996.

[2] J. Santiago, J. G. Oliveira, J. Lundin, A. Larsson, H. Bernhoff, Losses in Axial-Flux 
Permanent-Magnet Coreless Flywheel Energy Storage Systems, Proceedings of the 18th International Conference on Electrical Machines, Vilamoura, Portugal, 2008.

[3] M. Leijon, H. Bernhoff and B. Bolund, European Patent EP1565337.

[4] X. Liu, D. Diallo and C. Marchand, Design methodology of fuel cell electric vehicle power system, IEEE International Conference on Electrical Machines, Villamoura, Portugal, 2008.

[5] B. Szabados and U. Schaible, Peak power bi-directional transfer from high speed flywheel to electrical regulated bus voltage system: A practical proposal for vehicular technology, IEEE Trans. on Energy Conversion, 1998, vol. 13, no1, pp. 34-41.

[6] A. Chiba, T. Fukao, O. Ichikawa, M. Oshima, M. Takemoto, D.G. Dorrell, Magnetic Bearings and Bearingless Drives, ISBN 978-0-7506-5727-3, Oxford, Elsevier Newnes, 2005

[7] B.C.D. Wilson, Control Designs for LowLoss Active Magnetic Bearing: Theory and Implementation, etd-04122004-133631, Georgia, Georgia Tech Electronic Thesis and Dissertation Archive, 2004

[8] J. Santiago, A. Larsson, H. Bernhoff, Circuit Modeling of a Two Voltage Levels Machine, IEEE Trans. on Energy Conversion. Submitted for publication

[9] E. F. Fuchs, L. T. Rosenberg, Analysis of an Alternator with Two Displaced Stator Windings, IEEE Trans. on Power Apparatus and Systems, Volume: PAS-93, Issue: 6, Nov. 1974.

[10] T. M. Jahns, Motion Control with Permanent-Magnet AC Machines, Proceedings of the IEEE, Vol.82, No.8, August 1994.

[11] Sinusoidal Control of PMSM Motors with dsPIC30F DSC, Application Note 1017, Microchip, December 2005.

[12] K. Zhou, D. Wang., Relationship between space-vector modulation and three-phase carrier-based PWM: a comprehensive analysis, IEEE Trans. on Ind. Electronics. V 49, Issue 1, Feb 2002, pp 186-196.

[13] D. P. Atherton, Auto tuning of Phase Advance Controllers, Proceedings of the 4th IEEE Conference on Control Applications, pp 148-149, 1995.

\section{Authors}

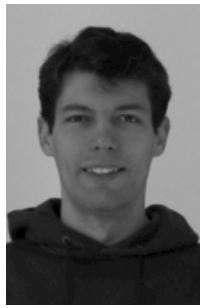

Juan de Santiago was born in Madrid, Spain. Received M.Sc. degree in Industrial Engineering from Universidad Politécnica de Madrid, Spain, in 2005. He is now a $\mathrm{PhD}$ student specialized in electrical machines for energy storage applications.

Janaína Gonçalves de Oliveira was

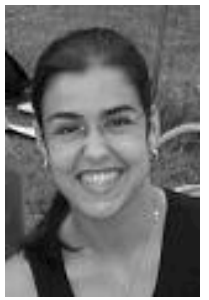
born on November 1983 in Juiz de Fora, Brazil. She received the degree in electrical engineering from the Federal University of Juiz de Fora, Minas Gerais, in February 2007. Since March 2007 she has been a Ph.D. student at the Division for Electricity at the Uppsala University, Sweden.

Johan Lundin was born in 1976 and raised in Härnösand, Sweden. B.Sc. in

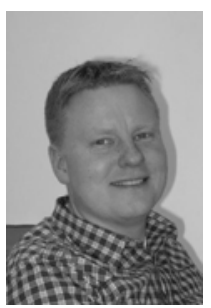
Economy (2003). M.Sc. in Aquatic and Environmental Engineering (2007) at Uppsala University, Sweden in 2007. After several years working at the Swedish Environmental Protection Agency, since 2007 he is a Ph.D. student, specialized on the system aspects of the driveline.

Johan Abrahamsson was born in Uppsala, Sweden, on December 4, 1977. He received the M.Sc. degree in engineering physics from Uppsala University, in 2004.

From 2002 to 2008, he worked for ABB in different positions.

Since 2008 he has been a Ph.D. student at the division for electricity at the Uppsala University.

Anders Larsson was born in Stockholm, Sweden, in 1963. MSc in Engineering Physics (1989), $\mathrm{PhD}$ in Electricity (1997), Assoc. Professor (2002), Adjunct Professor (2006-9), Uppsala University. $\mathrm{He}$ has held engineering/scientific positions at ABB Transformers AB, the Swedish Transmission Research Institute, Office National d'Etudes et de Récherches Aérospatiales (ONERA, France) and Lund Institute of Technology. From 2001 he is with the Swedish Defence Research Agency where he in 2003 was appointed Research Director in the area of Electrophysics and Pulsed Power. He has more than 100 publications in scientific journals and conference proceedings. 
Hans Bernhoff received the Ph.D. degree in the characterization and synthesis of high-temperature superconductors from the Royal Institute of Technology, Stockholm, Sweden, in 1992. In 1992, he held a postdoctoral position with the IBM Research Laboratory, Rueschlikon, Switzerland. In 1993, he joined ABB Corporate Research, Västerås, Sweden, where he worked as a Project Leader for several innovative projects in the area of electrotechnology, particularly in research on singlecrystal diamond as a wide-bandgap semiconductor. In 2001, he was appointed as an Associate Professor with Uppsala University, Uppsala, Sweden, in the area of highperformance systems. 